\title{
A Training Program to Enhance Postgraduate Students' Research Skills in Preparing a Research Proposal in the Field of Curriculum and Instruction Methods of Arabic Language
}

\author{
Dr. Ahmed Hassan Alfakih \\ College of Education, Albaha University, Saudi Arabia
}

\begin{abstract}
The study examined the impact of a training program on enhancing postgraduate students' research skills in preparing a research proposal. The nature of the skills required to prepare a research proposal were first determined using a questionnaire. A training program for improving such skills was then constructed and seven postgraduate students in the field of the curriculum and instruction methods of Arabic language participated in the program. The participants took a test before and after receiving the training. It was found that participants' relevant research skills improved between the pretest and posttest, indicating that an appropriate training program could contribute to enhancing such skills effectively. These results have implications for thesis supervisors, course designers, and postgraduate students, potentially assisting them to identify the research skills required for preparing a research proposal and to adopt and use the program as designed to improve such skills.
\end{abstract}

Keywords: postgraduate students, research proposal, research skills, training program

\section{Introduction}

The literature in the field of educational research asserts that the preparation of a research proposal (RP) for postgraduate degrees is important because it helps postgraduate students "... to demonstrate that the research [they] wish to undertake is significant, necessary and feasible, that [they] will be able to make an original contribution to the field, and that the project can be completed within the normal time period" (Department for Continuing Education at University of Oxford, 2017, para. 1). Preparing an RP is an essential part of the process of thesis preparation at the postgraduate level, which usually involves identifying a research topic, writing a proposal, conducting research, and writing up the thesis (Riazi, 2000; Wang \& Yang, 2012).

In addition, the preparation of an RP is difficult, for various reasons (Wang \& Yang, 2012); therefore, postgraduate students should pay close attention to preparing their RP, because it is expected to:

- show that [they] are engaging in genuine enquiry, finding out about something worthwhile in a particular context

- link [their] proposed work with the work of others, while proving [they] are acquainted with major schools of thought relevant to the topic

- establish a particular theoretical orientation

- establish [their] methodological approach, and

- Show [they] have thought about the ethical issues (Monash University, 2014, p. 2).

An effective RP should answer three main questions: What will be investigated? Why is the research needed? How is the problem going to be investigated? (Pietersen, 2014). According to Kivunja (2016), many universities around the world require candidates to prepare and write an RP in order to gain admission to research courses at the master's and $\mathrm{PhD}$ levels. Therefore, these universities have developed guidelines on preparing and writing an RP effectively. Moreover, there exist many specialized books on research methodology that elucidate in detail the components of an RP and the procedures for writing one. A review of university guidelines for preparing an RP in the field of education (e.g. Department for Continuing Education at University of Oxford, 2017; Library, Teaching and Learning at Lincoln University, 2016; Monash University, 2014; School of Education at University of Aberdeen, 2013) and of textbooks on educational research methodology (e.g. Ary, Jacobs, Sorensen, \& Razavieh, 2010; Dawson, 2002; Fraenkel \& Wallen, 2009; Kumar, 2011; Lodico, Spaulding, \& Voegtle, 2010) indicates that there is no "one-size-fits-all" RP (Kivunja, 2016, p. 163), but these sources agree generally that an effective RP has five main components, each with a specific function, as listed in Table 1. 
Table 1. The main components of a research proposal and their functions

\begin{tabular}{|c|c|c|}
\hline Component & Subcomponent & Function \\
\hline 1. Cover page & ---- & - Identifying topic, writer, institution and degree \\
\hline 2. Introduction & $\begin{array}{l}\text { 2.1 Background } \\
\text { 2.2 Need for study/ } \\
\text { rationale } \\
2.3 \text { Aim and objectives } \\
2.4 \text { Research questions/ } \\
\text { hypotheses } \\
\text { 2.5 Significance/ } \\
\text { expected outcomes }\end{array}$ & $\begin{array}{l}\text { - Answering WHAT questions, including providing background } \\
\text { information about the context of the study. } \\
\text { - Answering WHY questions, including persuading the reader that the } \\
\text { study is needed and will be useful/interesting. } \\
\text { - Stating clearly and succinctly the aim and objectives of the study. } \\
\text { - Formulating research questions/ hypotheses. } \\
\text { - Answering SO WHAT questions, including on the significance of the } \\
\text { study and expected outcomes }\end{array}$ \\
\hline $\begin{array}{l}\text { 3. Review of } \\
\text { literature }\end{array}$ & ---- & $\begin{array}{l}\text { - Providing a brief review of significant literature and current research in } \\
\text { the field and indicating on which issues/topics the full review will focus }\end{array}$ \\
\hline 4. Methodology & $\begin{array}{l}\text { 4.2 Timetable/Plan } \\
\text { 4.3 Proposed thesis } \\
\text { structure }\end{array}$ & $\begin{array}{l}\text { - Answering HOW, WHEN, WHERE, and WHO questions, including } \\
\text { outlining and describing the type of information and sources to be used, } \\
\text { the main methods/instruments to be employed and when and where, data } \\
\text { collection and analysis procedures, study subjects or participants, and any } \\
\text { ethical or safety issues identified. } \\
\text { - Depicting the tasks proposed and the stages/times for their completion. } \\
\text { - Describing the sequence and focus of each proposed chapter }\end{array}$ \\
\hline 5. References & ---- & $\begin{array}{l}\text { - Listing all publications cited in the proposal, using a suitable academic } \\
\text { referencing style. }\end{array}$ \\
\hline
\end{tabular}

Table 1 suggests that the essential components of an RP and their functions are evident and can be straightforwardly identified, yet a number of studies assert that postgraduate students face problems, difficulties and challenges when preparing RPs. For instance, Wang and Yang (2012) conducted a study in China to examine how six postgraduate students of a TEFL program learned to write their MA thesis RPs in English on a dedicated course. The students were found to face difficulties such as choosing a research topic, designing the $\mathrm{RP}$, understanding the style of a thesis RP, and reviewing the literature critically. The researchers conclude that postgraduate students should take courses in research methodology to help them to prepare their RPs and that they should be given support and encouragement on writing an RP. Pietersen (2014) explored content issues in the RPs of master's degree students in South Africa and found that participants lacked in-depth understanding of the components of an RP and failed to acknowledge the importance of concentrating on a central research question. Accordingly, he recommends that academic institutions should provide postgraduate students with tools, skills and practice in effective RP writing. Manchishi, Ndhlovu and Mwanza (2015) performed a qualitative study to identify the common mistakes that postgraduate students in Zambia made when writing RPs. These were found to involve the choice of topics that were unclear and too wide, indistinct problem statements, poor literature reviews, inappropriate research methodology, misunderstanding of research terminology, incorrect referencing style, and plagiarism. The authors conclude that research methodology courses should be revised to cover these important aspects of writing and preparing an RP. Another qualitative study, by Ahmed and Mahboob (2016), analyzed the difficulties faced by postgraduate students in Pakistan when writing RPs. They found that these included issues related to composing the background/introduction section, formulating research questions, selecting the appropriate research methodology and methods of data collection, and writing references. Therefore, the researchers propose that universities should organize more research methodology courses and writing workshops and should establish well-equipped research facilitation centers to help students address the challenges of preparing RPs. Finally, Kivunja (2016) found through his experience as a supervisor that many postgraduate students struggled to write good RPs. In response, he conducted a theoretical study to determine the components of a good RP and to explain in detail the correct procedures to guide postgraduate students in writing RPs effectively.

\subsection{Research Problem}

As an academic supervisor of master's degree students, I have found that they tend to lack the knowledge and skills required for writing an RP, leading them to face various difficulties and challenges in doing so. Moreover, my department offers no courses that concentrate specifically on enhancing students' RPwriting knowledge and skills; nor does it appear interested in providing support through training programs, workshops, and so on to help these students to address the difficulties that I have observed. According to Pietersen (2014), writing an RP is not easy; therefore, postgraduate students will need specific research skills to do so effectively. However, a review of some relevant literature on preparing and writing an RP reveals a lack of studies aimed specifically at identifying such skills; rather, the literature reviewed (e.g. Ahmed \& Mahboob, 2016; Kivunja, 2016; Manchishi et al., 2015; Pietersen, 2014; Wang \& Yang, 2012) discusses various aspects of 
RPs themselves. In addition, Pietersen (2014) points out that scholars have argued that postgraduate students cannot enhance their research skills for RP writing by depending on reading research methodology textbooks alone; during their studies they should also attend academic courses designed to equip them with the necessary knowledge and practical skills to write an RP. In this regard, Wang and Yang (2012) suggest that situated learning theory represents an appropriate strategy for improving postgraduate students' RP writing skills. According to Stein (1998), situated learning generally takes place through activities and relationships among students and instructors, rather than by acquiring information directly from discrete courses and programs arranged by institutions or instructors.

Based upon the above considerations, the present study set out to identify the research skills required for preparing an RP and to develop a training program to enhance such skills among postgraduate students, as will be discussed later. Situated learning theory was adopted as the theoretical framework. Accordingly, it was supposed that participants would enhance their research skills for preparing an RP by participating in the training program, because it would contribute to directing them to interact with their supervisors and friends during the process of preparing an RP, thus improving the required research skills and helping them to address the associated difficulties and challenges.

\subsection{Research Objectives}

In light of the above-stated problem, the main purpose of the present study was to examine the impact of a training program for enhancing postgraduate students' research skills in preparing an RP. From this main purpose the following two objectives were identified:

1. To identify the research skills required for preparing an RP.

2. To determine the impact of a training program in enhancing postgraduate students' research skills in preparing an RP.

\subsection{Research Questions}

To achieve the above two research objectives, the following two research questions were addressed:

1. What are the research skills required for preparing an RP?

2. What is the difference between participants' levels of research skills for preparing an RP before and after participating in a training program?

\subsection{Significance of the Study}

This study is expected to have major significance, both theoretical and practical. From the theoretical perspective, it will help supervisors, course designers, and postgraduate students to identify the research skills required for preparing an RP. From a practical perspective, the training program developed during the study will be able to be adopted and implemented at universities to improve postgraduate students' skills in RP preparation.

\section{Research Methodology}

The study adopted a quasi-experimental one-group pretest-posttest design. The following sections explain the selection of participants, the methods of data collection and the construction of the training program.

\subsection{Participants}

The study population comprised postgraduate students in the Department of Curriculum and Instruction Methods at the College of Education, Albaha University, Saudi Arabia. The Department offers a master's program with a choice of majors. The study sample was limited to students majoring in Curriculum and Instruction Methods of Arabic Language, of whom there were seven: four males and three females. The sample was limited to these seven students because increasing the number of participants might have prevented them from taking full advantage of a training program designed to enhance their research skills in preparing an RP.

\subsection{Data Collection}

Two methods were used to collect data: a questionnaire and a test.

\subsubsection{Questionnaire}

A questionnaire (see Appendix A) was used as an appropriate method to identify the research skills required for preparing an RP. Participants were asked to rate their level of ability in 20 such skills, which had been identified from a review of the relevant literature, as explained above. Three experts in research methodology were asked to review the research skills included in the questionnaire; they provided some valuable suggestions that involved changing some phrases to make the descriptions of the skills more easily readable and understandable. The questionnaire was then piloted to seven postgraduate students in order to elicit their views on the clarity of the items and to verify their reliability. The students asserted that all of the research 
skills were clearly described and Cronbach's alpha showed that the internal consistency value of the questionnaire for the 20 items was $\alpha=.94$. This value indicates that the questionnaire was clearly internally consistent and reliable (Pallant, 2007).

\subsubsection{Test}

In order to determine their level of ability in the 20 skills identified by means of the questionnaire, the participants underwent a test of these skills, which rated each student on each skill as poor, satisfactory, good, very good, or excellent. The test was applied to the participants before and after they undertook a training program designed to improve their research skills in preparing an RP. The test results are discussed after a description of the training program.

\subsection{Constructing the Training Program}

A training program to enhance postgraduate students' level of ability in the research skills needed to prepare an RP was constructed as follows.

1. The research skills for preparing an RP were determined by using the questionnaire.

2. The selection of the content and activities of the training program was based on a review of the literature on preparing and writing RPs.

3. These elements of the training program were uploaded to a website and study participants were asked to visit the site and read the content and activities of the training program.

4. Participants took the test described above to assess their pre-training level of ability in each of the research skills listed in Appendix A.

5. The participants took part in the training program.

6. They then took a second test in order to assess the impact of the training program in enhancing their research skills for preparing an RP.

\section{Findings And Discussions}

This section discusses the answers to each of the two research questions in light of the previous literature.

\subsection{The Research Skills Required for Preparing an RP}

The first research question aimed to identify the research skills required for preparing an RP. As mentioned above, no existing studies were found to have aimed specifically to determine these skills, although a number do examine the problems, difficulties and challenges confronting postgraduate students in preparing RPs (e.g. Ahmed \& Mahboob, 2016; Kivunja, 2016; Manchishi et al., 2015; Pietersen, 2014; Wang \& Yang, 2012). Accordingly, a questionnaire was used to address this research question. The findings (see Appendix A) revealed that there were 20 research skills required for preparing an RP, these being entirely consistent with those mentioned in previous studies.

\subsection{The Impact of the Training Program in Enhancing the Research Skills Needed for Preparing an RP}

The second research question concerned the impact of the training program in enhancing the level of participants' ability in the research skills needed for preparing an RP. This was assessed by using the pairedsamples t-test to compare the mean pretest score with the mean posttest score on these skills. The results are presented in Table 2.

Table 2. Results of paired-samples t-test for pre- and posttest scores

\begin{tabular}{|lllllll|}
\hline & $n$ & $M$ & $S D$ & $t$ & $d f$ & $p$ \\
\hline Pretest & 7 & 52.14 & 15.50 & -2.69 & 6 & .03 \\
Posttest & 7 & 68.28 & 8.44 & & & \\
\hline
\end{tabular}

These results indicate that participants in the training program had improved scores in the research skills for preparing an RP: $t(6)=-2.69, p=.03$. This is because the mean pretest and posttest scores were 52.14 $(S D=15.50)$ and $68.28(S D=8.44)$ respectively. As mentioned above, participants lacked both the knowledge and the practical skills needed to prepare an effective RP; however, the above results show that the training program designed as part of the study was able to contribute to improving these skills, for various reasons. First, the program was developed according to participants' needs with respect to the research skills in question. Second, the content and activities were designed effectively, because they concentrated on providing the participants with knowledge and skills likely to direct them to prepare and write an RP according to the correct procedures. The results of this study are consistent with those of previous studies (e.g. Ahmed \& Mahboob, 2016; Manchishi et al., 2015; Pietersen, 2014), which have concluded that academic institutions should equip postgraduate students with appropriate courses, programs and activities to enhance their knowledge and skills so 
that they can prepare RPs more effectively. Finally, the above results are in line with situated learning theory (e.g. Stein, 1998; Wang and Yang, 2012), which asserts that the interaction between supervisors and students will contribute effectively to improving postgraduate students' research skills for preparing an RP and to address the difficulties and challenges that they face when doing so.

\section{Conclusions And Implications}

This study has examined the impact of a training program for enhancing postgraduate students' research skills in preparing an RP in the field of the curriculum and instruction methods of Arabic language. The findings have several implications in the context of research at postgraduate level in countries such as Saudi Arabia. First, students at postgraduate level should possess the research skills needed to prepare an effective RP and their supervisors should have a clear perception of the necessary skills; the present study has contributed to determining such skills. Second, postgraduate students need to acquire specific knowledge and practical skills in order to prepare an RP effectively; the training program referred to in this study can be used to achieve this objective. Third, the designers of academic courses at universities will be able to develop the content and activities of research methodology courses for postgraduate students according to the findings of this study. The present study having been limited to students at master's level in the field of the curriculum and instruction methods of Arabic language, it is suggested that further studies should investigate the effectiveness of the training program presented here when applied to students at the doctoral level and in other majors such as curriculum and instruction methods of religion, science, mathematics and so on. In addition, qualitative studies should be conducted to explore in depth the opinions of postgraduate students regarding the effectiveness of this training program in enhancing each of the research skills concerned, because the present study concentrated on examining its impact on all research skills for preparing an RP.

\section{References}

[1] Department for Continuing Education at University of Oxford (2017). Writing your research proposal. Retrieved from https://www.conted.ox.ac.uk/about/writing-your-research-proposal.

[2] Riazi, A. M. (2000). How to write research proposals. Tehran: Rahnama Publications.

[3] Wang, X., \& Yang, L. (2012). Problems and strategies in learning to write a thesis proposal: A study of six MA students in a TEFL program. Chinese Journal of Applied Linguistics, 35(3), 324-341.

[4] Monash University. (2014). Writing a proposal in education. Retrieved from https://www.monash.edu/_data/assets/pdf_file/0004/145822/booklet-writing-a-proposal-in-education.pdf.

[5] Pietersen, C. (2014). Content issues in students' research proposals. Mediterranean Journal of Social Sciences, 5(20), 1533-1541.

[6] Kivunja C. (2016). How to write an effective research proposal for higher degree research in higher education: Lessons from practice. International Journal of Higher Education, 5(2), 163-172. doi.org/10.5430/ijhe.v5n2p163.

[7] Library, Teaching and Learning at Lincoln University (2016). Writing a research proposal. Retrieved from https://ltl.lincoln.ac.nz/wp-content/uploads/sites/20/2016/02/Writing-a-research-proposal.pdf.

[8] School of Education at University of Aberdeen (2013). What is a research proposal? Retrieved from https://www.abdn.ac.uk/education/documents/Guidelines_for_Research_Proposal.pdf.

[9] Ary, D., Jacobs, L. C., Sorensen, C., \& Razavieh, A. (2010). Introduction to research in education (8th ed.). Cengage Learning.

[10] Dawson, C. (2002). Practical research methods: A user-friendly guide to mastering research techniques and projects. Oxford: How To Books.

[11] Fraenkel, J. R., \& Wallen, N. E. (2009). How to design and evaluate research in education (7th ed.). New York, NY: McGraw-Hill.

[12] Kumar, R. (2011). Research methodology: A step-by-step guide for beginners (3rd ed.): SAGE Publications.

[13] Lodico, M. G., Spaulding, D. T., \& Voegtle, K. H. (2010). Methods in educational research: From theory to practice (2nd ed.). San Francisco, CA: Jossey-Bass.

[14] Manchishi, P.C., Ndhlovu, D., \& Mwanza, D. S. (2015). Common mistakes committed and challenges faced in proposal writing by University of Zambia postgraduate students. International Journal of Humanities Social Sciences and Education, 2(3), 126-138.

[15] Ahmed, F., \& Mahboob, U. (2016). An analysis of research proposals and challenges faced by postgraduate trainees in internal medicine and allied disciplines during fellowship training program: A qualitative study. Khyber Medical University Journal, 8(2), 82-87.

[16] Stein, D. (1998). Situated learning in adult education. ERIC (ED418250)

[17] Pallant, J. (2007). SPSS survival manual: A step by step guide to data analysis using SPSS for Windows (3rd ed.). Open University Press. 


\section{Appendix A}

Questionnaire on Research Skills for Preparing a Research Proposal

\begin{tabular}{|c|c|c|c|c|c|}
\hline \multirow[b]{2}{*}{ Research Skill } & \multicolumn{5}{|c|}{ What is your level in the skill? } \\
\hline & $\stackrel{8}{8}$ & 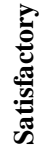 & 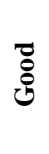 & $\begin{array}{l}\overrightarrow{0} \\
\text { D. } \\
\text { D. } \\
\overrightarrow{0} \\
\overrightarrow{0}\end{array}$ & 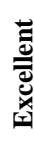 \\
\hline 1. Identifying general research area of interest. & (0) & (1) & (2) & (3) & (4) \\
\hline $\begin{array}{l}\text { 2. Using different information sources to find literature that is associated with the } \\
\text { general research area. }\end{array}$ & (1) & (1) & (2) & (3) & (4) \\
\hline 3. Using critical reading skills to read and summarize the contents of the literature. & (0) & (1) & (2) & (3) & (4) \\
\hline 4. Using critical thinking skills to analyze the contents of the literature. & (0) & (1) & (2) & (3) & (4) \\
\hline 5. Selecting a research topic. & (0) & (1) & (2) & (3) & (4) \\
\hline 6. Providing background information about the context of the study. & (1) & (1) & (2) & (3) & (4) \\
\hline 7. Formulating the statement of the problem. & (1) & (1) & (2) & (3) & (4) \\
\hline 8. Determining the purpose of the study. & (1) & (1) & (2) & (3) & (4) \\
\hline 9. Determining research objectives. & (0) & (1) & (2) & (3) & (4) \\
\hline 10. Formulating research questions/hypotheses. & (0) & (1) & (2) & (3) & (4) \\
\hline 11. Defining significance of the study. & (1) & (1) & (2) & (3) & (4) \\
\hline 12. Explaining limitations of the study. & (0) & (1) & (2) & (3) & (4) \\
\hline 13. Defining operational terms. & (0) & (1) & (2) & (3) & (4) \\
\hline 14. Reviewing and analyzing previous literature. & (0) & (1) & (2) & (3) & (4) \\
\hline 15. Describing research methodology/design. & (0) & (1) & (2) & (3) & (4) \\
\hline 16. Determining subjects or participants in the study. & (1) & (1) & (2) & (3) & (4) \\
\hline 17. Determining and describing research methods/instruments. & (1) & (1) & (2) & (3) & (4) \\
\hline 18. Explaining data collection procedures. & (0) & (1) & (2) & (3) & (4) \\
\hline 19. Explaining data analysis approaches. & (0) & (1) & (2) & (3) & (4) \\
\hline 20. Using a suitable academic style to format list of references. & (0) & (1) & (2) & (3) & (4) \\
\hline
\end{tabular}

